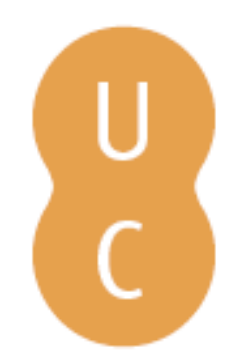

\title{
pommalina
}

\section{O Poeta Indefeso: símbolos de impotência na poesia ovidiana do exílio}

\begin{tabular}{ll} 
Autor(es): & Mora, Carlos de Miguel \\
Publicado por: & $\begin{array}{l}\text { Centro de Estudos Clássicos e Humanísticos; Imprensa da Universidade } \\
\text { de Coimbra }\end{array}$ \\
$\begin{array}{ll}\text { URL } \\
\text { persistente: }\end{array}$ & URI:http://hdl.handle.net/10316.2/31685 \\
DOI: & DOI:http://dx.doi.org/10.14195/978-989-8281-47-0_10 \\
Accessed : & 26-Apr-2023 14:41:41 \\
\hline
\end{tabular}

A navegação consulta e descarregamento dos títulos inseridos nas Bibliotecas Digitais UC Digitalis, UC Pombalina e UC Impactum, pressupõem a aceitação plena e sem reservas dos Termos e Condições de Uso destas Bibliotecas Digitais, disponíveis em https://digitalis.uc.pt/pt-pt/termos.

Conforme exposto nos referidos Termos e Condições de Uso, o descarregamento de títulos de acesso restrito requer uma licença válida de autorização devendo o utilizador aceder ao(s) documento(s) a partir de um endereço de IP da instituição detentora da supramencionada licença.

Ao utilizador é apenas permitido o descarregamento para uso pessoal, pelo que o emprego do(s) título(s) descarregado(s) para outro fim, designadamente comercial, carece de autorização do respetivo autor ou editor da obra.

Na medida em que todas as obras da UC Digitalis se encontram protegidas pelo Código do Direito de Autor e Direitos Conexos e demais legislação aplicável, toda a cópia, parcial ou total, deste documento, nos casos em que é legalmente admitida, deverá conter ou fazer-se acompanhar por este aviso.

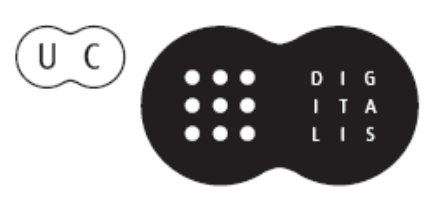




\section{Sociedade, Poder e Cultura no Tempo de Ovídio}

Maria Cristina de Sousa Pimentel e Nuno Simões Rodrigues (Coords.) 


\title{
O Poeta Indefeso: SÍMBOLOS DE IMPOTÊNCIA NA POESIA OVIDIANA DO EXÍLIO
}

\author{
Carlos de Miguel Mora \\ Universidade de Aveiro
}

Quando Ovídio recebe a inesperada notícia da sua expulsão de Roma, no ano 8 da nossa era, contava cinquenta anos e era, pode dizer-se com toda a justiça, o principal poeta de Roma. A sua vasta e densa obra abrangia diversos géneros e tinha avançado, progressivamente, desde o «género menor» da elegia até à etiologia praticada nos Fasti. No entanto, podemos dividir a sua produção basicamente em dois grupos: uma poesia relacionada de alguma maneira com a elegia e uma poesia de grande fôlego (deixando de lado a tragédia Medea, da qual praticamente nada sabemos). Na primeira, além dos Amores, incluiremos as Heroides, espécie de variação sobre o tema, com a troca de sujeito poético, e a poesia erotodidáctica, desenvolvimento de um dos tópicos da elegia, o magisterium amoris. A segunda abrangeria a obra claramente épica das Metamorphoses e o calendário romano dos Fasti, ambas sob a inspiração da etiologia calimaqueia.

No momento imediatamente anterior à sua relegatio, é este último tipo de poesia que está a escrever. No entanto, o Sulmonense volta à poesia elegíaca quando decide escrever essa literatura qualificada por muitos como «de queixa» (e, de facto, o tópico da querimonia está sempre presente). Ovídio escreve a poesia do exílio de uma maneira semelhante à amorosa; na verdade, os poemas do exílio são epístolas elegíacas, do mesmo modo que o foram as Heroides, pelo que se tratava da continuidade de um género com um tópico diferente. Continuidade com esse tipo de poesia e quebra com a poesia elevada, que é interrompida de forma brusca ${ }^{1}$. O poeta não permite que o leitor esqueça que se trata de poesia elegíaca e que existe uma continuidade com a poesia amorosa escrita nos inícios da sua carreira poética ${ }^{2}$. Para lembrar esta identidade utiliza uma estratégia mais ou menos óbvia e outra menos evidente.

A estratégia a que chamamos óbvia consiste em, por um lado, mencionar de forma clara que a obra mais importante do poeta é a obra elegíaca e que a outra, ao contrário, ficou cortada; e por outro lado em lembrar, de quando em quando, que a métrica usada é o dístico elegíaco.

Podemos ver alguns exemplos para compreender bem esta estratégia. $\mathrm{O}$ primeiro ponto do que acabamos de dizer está mais ou menos claro no poema

${ }^{1}$ Cf. NAgle (1980) 19-20. Como explica a autora, continuar com a poesia elevada teria prejudicado as intenções do poeta, que queria chamar a atenção para a sua precária situação. As tentativas de despertar a comiseração do imperador não se coadunavam com uma poesia grandiosa.

${ }^{2}$ Este facto, de certa maneira, constitui um paradoxo, se se tem em consideração que o carmen que provocou a desgraça de Ovídio deve ter sido a Ars amatoria, como parece claro em várias passagens. Porque quer o poeta reforçar a sensação de que está a escrever o mesmo tipo de poesia que o condenou? 
10 do quarto livro dos Tristia, o famoso poema autobiográfico. Já no primeiro verso chama a si próprio de tenerorum lusor amorum; no conhecido dístico 53-54 estabelece a sua filiação poética na linha dos autores elegíacos ${ }^{3}$; menciona a seguir que leu poemas ainda novo (cf. vv. 57-58), que cantou na sua obra uma mulher sob o pseudónimo de Corina (cf. v. 60), e que o seu coração era mole e sensível às setas de Cupido (cf. vv. 65-66). Nada nos diz da sua obra mais elevada neste poema. E, pelo contrário, noutras composições chama a atenção para a quebra que o exílio supôs para a escrita das Metamorphoses ${ }^{4}$ e dos Fasti ${ }^{5}$. Quanto à constante lembrança de estar a escrever dísticos, podemos ver dois dos muitos exemplos que se poderiam encontrar na poesia do exílio:

Clauda quod alterno subsidunt carmina uersu, uel pedis hoc ratio, uel uia longa facit; 6

Se os meus poemas assentam, / coxos, em verso alternado, o culpado será o pé, / ou o caminho prolongado ${ }^{7}$

et tamen ad Musas, quamuis nocuere, reuerti, aptaque in alternos cogere uerba pedes. ${ }^{8}$

que às Musas que me lesaram / voltei mesmo assim outra vez e faço encaixar palavras / moldadas a alternos pés.

A estratégia menos evidente consiste na adequação da elegia do exílio às formas previamente existentes para a elegia erótica. Nagle demonstrou que existem muitos pontos de contacto entre os dois tipos de elegia, quer temática quer formalmente'.

Pretendemos apoiar aqui a tese defendida por esta autora, centrando-nos numa outra coincidência entre a poesia amorosa de Ovídio e a da sua relegatio:

${ }^{3}$ successor fuit hic (sc. Tibullus) tibi, Galle, Propertius illi;

quartus ab his serie temporis ipse fui.

${ }^{4}$ Cf. Tr. 1.7.13-14:

carmina mutatas hominum dicentia formas,

infelix domini quod fuga rupit opus.

${ }^{5}$ Cf. Tr. 2.551-552:

idque tuo nuper scriptum sub nomine, Caesar,

et tibi sacratum sors mea rupit opus.

Como se pode verificar, os dois pentâmetros apresentam uma extraordinária semelhança.

${ }^{6} \operatorname{Tr} \cdot 3 \cdot 1 \cdot 11-12$.

${ }^{7}$ Para os textos dos Amores segui a tradução publicada por André (2006). Para os textos dos Tristia e das Epistulae ex Ponto, não tendo encontrado traduções portuguesas, apresento uma proposta minha.

${ }^{8}$ Tr. 3.7.9-10.

${ }^{9}$ Cf. NAgle (1980) 43-68. Entre os temas que salienta a autora estão, por exemplo, a adaptação das características da amada elegíaca à sua mulher, do Amor pharetratus pelo Getes pharetratus, tópicos como o da militia amoris. Quanto ao léxico, insiste no especializado para o estado de ânimo do amante, agora transferido para o do poeta exilado. 
a situação de impotência, de incapacidade de defesa, em que se encontra o poeta, e a sua expressão literária. Que o poeta se mostre indefeso, incapaz de se confrontar com a sua situação, é um facto muito conhecido da poesia ovidiana do desterro. Interessa-nos aqui mostrar que a forma como esta impotência ou incapacidade de defrontar a sua condição se expressa não é muito diferente daquela que podemos encontrar na poesia amorosa, especificamente nos Amores. E isto acontece numa dupla vertente: na impotência anímica e na impotência física do amante.

Comecemos pelos paralelos entre a impotência do poeta exilado e a impotência anímica do amante. $\mathrm{O}$ primeiro indício da incapacidade defensiva aparece logo no início dos Tristia. No poema que abre a colecção (Tr. 1.1), o autor dirige-se ao próprio livro, numa espécie de propemptikon, desejando-lhe uma boa viagem à Urbe e encomendando-lhe o que deve fazer e aonde se deve dirigir, visto que the está vedado fazê-lo ele próprio. $\mathrm{O}$ livro transforma-se num mensageiro necessário, ao qual o seu dono dirige estas palavras iniciais (Tr.1.1.1-2):

Parue-nec inuideo—sine me, liber, ibis in urbem: ei mibi, quod domino non licet ire tuo!

Sem mim, e eu não te invejo, / irás à Urbe, livrinho: ai de mim!, porque ao teu dono / está vedado o caminho.

A impotência do poeta, que vê proibido um caminho ao qual apenas os seus livros têm acesso, lembra o mesmo desespero mostrado em Amores 3. 8. Se no poema do exílio Ovídio tem vedada a entrada em Roma e precisa de uma delegação no seu livro, o único a quem esta está permitida, já no poema da elegia amorosa o poeta mostra a sua frustração porque a sua amada lhe impede a entrada em casa, enquanto para os livros a passagem está livre. No primeiro caso, o que proíbe o caminho é a pena imposta pelo Imperador pelo crimen ovidiano; no segundo, a amada veta a entrada pela condição de pobreza do poeta (Am.3.8.3-6):

ingenium quondam fuerat pretiosius auro;

at nunc barbaria est grandis, habere nibil.

cum pulchre dominae nostri placuere libelli, quo licuit libris, non licet ire mibi; ${ }^{10}$

O engenho, em tempos idos, era mais precioso que o ouro, mas, agora, imensa barbárie é nada possuir.

Apesar de os meus livros agradarem lindamente à minha amada, onde aos livros foi consentido entrar, a mim não foi consentido.

${ }^{10}$ Sem pretender dizer que todas as coincidências lexicais são propositadas, gostaria de chamar a atenção para o léxico que se repete nos textos que propomos para análise comparativa, salientado pela utilização de negrito. 
O poeta vive numa constante situação de desespero. Para reflectir o seu naufrágio interior, narra, em duas das quatro primeiras composições ( $\operatorname{Tr} .1 .2$ e 1.4), dois relatos de tempestade durante a viagem. Na última destas (1.4) encontramos um léxico muito significativo, já que aparece de forma abundante nos poemas programáticos iniciais de Amores. Vejamos alguns fragmentos desta composição (Tr. 1.4.5-6; 11-12; 25-28):
me miserum! quantis increscunt aequora uentis, erutaque ex imis feruet harena fretis! (...)
nauita confessus gelidum pallore timorem, iam sequitur uictus, non regit arte ratem (...)
parcite caerulei uos parcite numina ponti, infestumque mibi sit satis esse Iouem.

Com que ventos poderosos, / ai de mim!, aumenta o mar e das grandes profundezas / sai a areia a fervilhar!

A lividez do marujo / denuncia um temor frio, deixa-se levar, vencido, / sem poder sobre o navio

Poupai-me, numes do Ponto, / poupai-me vós, divindades, já me chega o ter de Jove / funestas hostilidades.

O que há de mais significativo neste fragmento? Precisamente que o léxico é usado por Ovídio nas suas insinuações metapoéticas de Amores. Como dissemos noutro lugar ${ }^{11}$, Ovídio constrói na sua obra amorosa duas personagens diferentes, um amator e um poeta ${ }^{12}$, mas o primeiro interfere, por assim dizer, nas tarefas do segundo. Ao ser atingido pelas setas de Cupido, exclama Ovídio em $A m$. 1.1.25-26:

me miserum! certas habuit puer ille sagittas. uror, et in uacuo pectore regnat Amor.

Desgraçado de mim! Certeiras foram as setas daquele menino! Todo eu me inflamo, e no coração vazio passa a reinar o Amor.

Se Cupido obriga Ovídio a apaixonar-se, fá-lo para lhe dar um motivo de inspiração, ocupando o lugar das Piérides ou de Febo, como já tinha dito o narrador ingénuo. Logo depois de ser atingido pela seta transformase propriamente em amator, em amante elegíaco, pois a primeira coisa que faz é exclamar me miserum!, que evoca ao leitor atento o primeiro verso do Monobiblos properciano, Cynthia prima suis miserum me cepit ocellis, verso de grande acumulação de ideias programáticas. A seguir, constata que se queima

\footnotetext{
${ }^{11}$ Miguel Mora (2006) 59-78.

${ }^{12}$ A relação entre Ovídio poeta e Ovídio amator nos Amores é bem estudada por Holzberg (2002) 46-70.
} 
de amor (uror), seguindo um léxico absolutamente normal na literatura amorosa latina. No poema seguinte, $A m$. 1.2, encontramos uma grande insistência na dualidade vencedores/vencidos (vv.19-22):

En ego confiteor! tua sum nova praeda, Cupido; porrigimus victas ad tua iura manus.

nil opus est bello - veniam pacemque rogamus; nec tibi laus armis victus inermis ero.

Eis que reconheço: sou a tua nova presa, ó Cupido; estendo às tuas leis as minhas mãos vencidas.

Não há precisão de combate; perdão e paz é o que suplico, e não hás-de ter glória em vencer pelas armas um homem desarmado.

Nesta peça encontramos o poeta insone, duvidando se deve resistir ao amor, mas rendendo-se por fim; deste modo, dirige a Cupido uma alocução de rendição e descreve a pompa triunfal do deus que, à maneira dos generais vitoriosos, percorrerá as ruas de Roma. No fim do poema, Ovídio suplica ao deus (vv. 49-52):

Ergo cum possim sacri pars esse triumphi, parce tuas in me perdere, victor, opes! adspice cognati felicia Caesaris armaqua vicit, victos protegit ille manu.

Já que eu posso, portanto, ser parte do teu sagrado triunfo, poupa-te e não gastes em mim as tuas forças de vencedor; contempla os exércitos venturosos do César, teu parente;

por onde alcançou vitórias, os vencidos ele os protege com sua mão.

Dizíamos antes que o narrador amator interfere nas tarefas do poeta. Esta interferência é produzida porque o poeta joga ao transmitir conceitos metapoéticos dentro da própria história amorosa. Ovídio exprime a maneira como o amante elegíaco deve ser: deve padecer (miser), deve ser um derrotado na guerra amorosa (militia amoris), porque quem ganha, quem domina na relação amorosa é a amada ou, em todo o caso, Cupido, e o amante é o escravo de amor (seruitium amoris), e por isso um vencido, um derrotado nessa guerra (uictus), que apenas tem como último recurso para a sua impotência suplicar por misericórdia (parce). Não pode dever-se à casualidade que este léxico tão significativo e cheio de relevância metapoética se reproduza no caso paralelo de impotência do exilado, sobretudo num poema tão simbólico (e isto é aceite pela generalidade dos investigadores) como o poema 1.4. dos Tristia, onde a tormenta física reproduz metaforicamente a tormenta interior: o poeta exilado evoca, quando se encontra perdido, a condição de miserável própria do amante elegíaco (me miserum!). Afirma que o piloto foi vencido, razão pela qual governa sem arte a nave. Governar sem arte tem 
uma significação muito especial. Quando volta a lembrar a mesma situação, no poema 1.11 dos Tristia, Ovídio insistirá no facto de que o piloto estava inmemor artis, sem se lembrar da sua arte. $\mathrm{Na}$ guerra amorosa, o vencedor é quem domina a arte da sedução (Ars amatoria), e o perdedor, o vencido, é quem a desconhece. Finalmente, não existe outro remédio senão suplicar misericórdia (parcite) aos deuses do Ponto, como tivera de fazer com Cupido quando se encontrava apaixonado. A uma situação de impotência anímica amorosa corresponde assim, em termos semelhantes, uma de impotência anímica perante a injustiça da relegatio. Comprovamos que, mais uma vez, o poeta recorre a tópicos e léxico da poesia que mais bem conhece, aquela da qual é mestre, a amorosa, para reflectir uma situação nova mas que manifesta muitos pontos de contacto com a anterior.

Mas o que pode chamar mais a atenção é que, para exprimir a impotência do exilado, se recorra a uma recuperação de tópicos não da impotência anímica do amante mas da própria impotência física, a sexual. Retomemos uma das expressões que mencionámos anteriormente, inmemor artis, que se encontra no dístico 21-22 de Tr. 1.11:

\section{ipse gubernator tollens ad sidera palmas exposcit uotis, inmemor artis, opem.}

O piloto mesmo alçava, / esquecendo a profissão, os braços para as estrelas / e rogava proteç̧ão.

Como dissemos, Ovídio lembra nele a cena anterior da tormenta, salientando o mais importante da situação. É claro que, como aponta $\mathrm{Nagle}^{13}$, uma intenção clara do Sulmonense nesta passagem é apontar ao leitor que o poeta está a escrever (memor artis suae), enquanto o piloto esqueceu a ars dele, pelo qual salienta a sua firmeza de ânimo. Mas ars tem, na poesia ovidiana amorosa, dois sentidos que muitas vezes se justapõem, como fazem o narrador-poeta e o narrador-amante: arte de escrever e arte de seduzir. O piloto da nave encarna nos dois poemas a transposição para o exílio do desespero e da impotência do amante, vencido e ignorante das artes que lhe são próprias. Existe um poema nos Amores onde o termo inmemor é também referido num contexto de impotência sexual ( $\mathrm{Am}$. 3.7.73-78):

Hanc etiam non est mea dedignata puella molliter admota sollicitare manu; sed postquam nullas consurgere posse per artes inmemoremque sui procubuisse videt, "quid me ludis?» ait, "quis te, male sane, iubebat invitum nostro ponere membra toro?»

\footnotetext{
${ }^{13}$ NAGLE (1980) 47.
} 
A esta coisa aqui, a minha amada não se furtou, mesmo, a despertá-la, com doces movimentos da sua mão; mas, depois de não ser capaz de a levantar, fosse por que artes fosse, ao vê-la, ali, caída, deslembrada de si, disse:

«Porque troças de mim? Alguém te mandou, ó estupor, trazer, contrariado, o teu corpo para cima da minha cama?»

Neste fragmento, o membro viril do poeta não consegue lembrar-se de si próprio, isto é, daquilo que era antes, nem sequer com o auxílio das artes amorosas da puella. Este poema, Am. 3.7, constitui uma raridade no conjunto da elegia latina, por estar dedicado a esta situação de impotência sexual ${ }^{14}$. Acompanhando o seu texto poderemos comprovar como os casos de impotência vital do exilado Ovídio são descritos em ocasiões com recurso a tópicos e vocabulário que recuperam em certo sentido os usados na impotência sexual do amante Ovídio. Podemos verificá-lo em vários exemplos.

No poema programático que abre os Amores, Cupido apresenta-se ao poeta com todo o seu fulgor, altaneiro, ambicioso, cruel, poderoso. Vejamos como exemplo Am.1.1.13-14, onde o poeta lhe critica as suas novas atribuições de inspirar os poetas:

sunt tibi magna, puer, nimiumque potentia regna; cur opus adfectas, ambitiose, novum?

Imensos são, ó menino, e bem poderosos os teus reinos; porque deitas a mão, cheio de avidez, a nova empresa?

Mas o mesmo deus apresenta-se de maneira muito diferente ao poeta exilado, como narra numa carta a Fábio Máximo (Pont. 3.3.13-16):

Stabat Amor, uultu non quo prius esse solebat, fulcra tenens laeua tristis acerna manu, nec torquem collo neque habens crinale capillo nec bene dispositas comptus ut ante comas.

Amor lá estava, o seu rosto / não como antes costumava: triste, e a sua mão esquerda / na velha cama apoiava, sem gargantilha o pescoço / o cabelo sem mais nada e sem compor como dantes / a juba bem penteada.

O poeta recebe o deus entre sonhos, mas a sua penosa situação tem reflexo nas preocupações que tenta disfarçar com esse descanso e no lamentável estado do seu corpo estendido lânguido sobre o leito (vv.7-8):

\footnotetext{
${ }^{14}$ Esta é mencionada noutros lugares da poesia elegíaca, como por exemplo Tib. 1.5.39-40: saepe aliam tenui, sed iam cum gaudia adirem, admonuit dominae deseruitque Venus,

mas são sobretudo alusões breves, nunca um poema completo como o ovidiano.
} 
Publica me requies curarum somnus babebat fusaque erant toto languida membra toro,

Estava preso do sono, / vulgar alívio da dor, por todo o leito estendia / membros cheios de torpor.

A expressão languida membra, com uma poderosa evocação sexual, lembra uma situação de impotência. De facto, $A m$. 3.7, começa deste modo:

At non formosa est, at non bene culta puella, at, puto, non votis saepe petita meis!

banc tamen in nullos tenui male languidus usus, sed iacui pigro crimen onusque toro;

É certo que não é formosa, é certo que não é muito elegante esta mulher, é certo, julgo eu, que não foi muitas vezes objecto de meus desejos;

mesmo assim, para desgraça minha, tive-a em meus braços relaxados, sem qualquer proveito, mas fiquei estendido, feito um traste e um peso na preguiça da cama.

Para dizer mais à frente, depois de um fragmento que acabámos de citar (Am. 3.7.77-78):

"quid me ludis?» ait, «quis te, male sane, iubebat invitum nostro ponere membra toro?»

«Porque troças tu de mim? Alguém te mandou, ó estupor, trazer, contrariado, o teu corpo para cima da minha cama?»

Mas podemos aprofundar ainda mais a maneira como o poeta expressa a sua impotência sexual e a sua impotência social no exílio para descobrir semelhanças reveladoras. Nesse mesmo fragmento inicial de $A m$. 3.7., após uma explicação de como ficava decaído, sem fazer adequado uso da rapariga que se lhe oferecia, descreve metaforicamente a maneira como se sentiu, como se fosse uma afronta ou um crime e até uma espécie de peso morto ou carga para o próprio leito. No primeiro dos termos não precisamos de insistir para compreender imediatamente a sua relação com a poesia do exílio. É bem sabido que dois crimina, um carmen e um error, foram as causas da desgraça ovidiana, e que a palavra se repete constantemente na poesia do exílio (57 vezes aparece a palavra crimen nos Tristia e Epistulae ex Ponto, sem contar por tanto In Ibin, mas só 25 vezes nos Amores; error, por exemplo, surge por 22 vezes nestas obras do exílio e apenas 2 vezes nos Amores). Mas chama ainda mais a atenção a sua denominação de onus, carga, peso morto, quando se apresenta como impotente. Da mesma maneira que se transformou numa carga para o leito e para a moça no momento da sua impotência sexual, assim se vê a si próprio em relação a um dos seus amigos em duas cartas, uma dos Tristia (5.6.1-6) e outra das Epistulae ex Ponto (2.3.73-74): 
Tu quoque, nostrarum quondam fiducia rerum, qui mibi confugium, qui mibi portus eras, tu quoque suscepti curam dimittis amici, officiique pium tam cito ponis onus? sarcina sum, fateor, quam si non tempore nostro depositurus eras, non subeunda fuit.

Também tu, que eras outrora / guardião dos meus assuntos, que foste para mim porto /seguro e refúgio juntos, também tu deixas agora / o cuidado da amizade, e tão cedo o santo peso / da responsabilidade? Confesso ser uma carga / mas se, o momento chegado, segurá-la não querias, / não devias tê-la aceitado.

quod cum uestra domus teneris mibi semper ab annis culta sit, esse uetus me tibi cogit onus.

E, tendo eu desde o berço / sempre a tua casa honrado, a ser para ti agora / velha carga sou forçado.

Dá-se a circunstância de que, quer numa quer noutra carta, se tem querido ver como destinatário Cota Máximo, isto apesar de os Tristia não terem interlocutor expresso e de, na epístola ex Ponto mencionada, apenas se dizer que vai dirigida a Máximo, sem especificar se se trata de Cota ou Fábio.

Outra metáfora que o poeta utiliza na mesma composição $(A m$. 3.7) é a da sombra, associada de novo ao peso morto. Com efeito, o poeta pergunta-se se nessa ocasião continuava a ser um corpo (activo) ou se se tinha transfigurado em apenas uma sombra (passiva) (Am.3.7.15-16):

truncus iners iacui, species et inutile pondus, et non exactum, corpus an umbra forem.

Ali fiquei estendido, inerte, um fantasma e um peso inútil; e nem se percebia se era um corpo ou uma sombra.

No terceiro livro dos Tristia, livro supostamente escrito durante o primeiro ano em Tomos, quando o Sulmonense começa a aceitar a ideia de que o exílio era mesmo a sério, a elegia 11 é a única dirigida a um inimigo, entre as muitas dedicadas a amigos. Aqui o poeta sente-se impotente perante uma personagem que o hostiliza à distância. Ovídio descreve a sua cruel situação, as suas penalidades, para mostrar a mesquinhez que significa atacar alguém caído, alguém que não consegue defender-se a si próprio, um poeta indefeso. Ao seguir este raciocínio, chega a dizer (Tr.3.11.25-26):

Non sum ego quod fueram. Quid inanem proteris umbram? quid cinerem saxis bustaque nostra petis? 
Porque pisas sombra estéril, / se não sou quem era dantes?

Porque é que atacas com pedras / as minhas cinzas restantes?

A sombra de um corpo, de um ser, é aquilo que fica depois da morte na maior parte das ideias religiosas romanas. Por isso, não deve estranhar-se que, continuando com essa ideia, o poeta impotente de $A m .3 .7$ se pergunte se está vivo, pois a falta de vigor sexual significa a falta de masculinidade e de vida (Am. 3.7.57-60):

illa graves potuit quercus adamantaque durum surdaque blanditiis saxa movere suis.

digna movere fuit certe vivosque virosque; sed neque tum vixi nec vir, ut ante, fui.

Ela, até pesados carvalhos e o diamante mais rijo e surdos penedos era capaz de despertar com suas meiguices;

e era também merecedora, por certo, de despertar tudo quanto é vivo e homem; mas eu não estava vivo nem era homem, como antes fora.

O poeta exilado também pergunta ao seu amigo Messalino se deve ser considerada vida essa espécie de morte que ele sofre, entre o frio e as setas dos Citas. A impotência do desterro tem reflexo nuns tópicos e num léxico que lembram as dúvidas que a impotência sexual semeou (Pont. 1.7.9-10):

\section{Non satis est inter glaciem Scythicasque sagittas uiuere, si uita est mortis habenda genus.}

Não chega entre setas citas / e este frio glacial do Norte, ter de viver (se por vida / tenho este tipo de morte).

Como vimos, Ovídio serve-se de muitos recursos habituais na sua elegia erótica para a composição da poesia do exílio. Não é nada de surpreendente num autor cuja complexidade conceitual atinge níveis tão elevados. $\mathrm{O}$ poeta será sempre o tenerorum lusor amorum, como se denomina a si próprio no terceiro livro dos Tristia (Tr. 3.3.73); escrevendo elegia (e o poeta empenhase em lembrar constantemente ao leitor que é elegia que escreve), tinha de recorrer à sua obra anterior. Nos Amores já tinha justaposto constantemente um significado erótico e outro metapoético, utilizando o léxico amoroso para a reflexão sobre a própria poesia. Não se esperava outra coisa senão que o poeta utilizasse na sua produção do exílio um material já provado com sucesso na poesia amorosa. A genialidade desta auto-imitação residia na economia literária, multiplicando os conceitos numa extensão reduzida, ao aproveitar símbolos, léxico, tópicos, da sua poesia anterior. Um dos âmbitos onde se produz esta economia de composição é o da frustração, a situação de indefeso, a impotência do exilado, motivo que, como se há-de supor, inunda toda a obra 
ovidiana do desterro e que, como pudemos comprovar, aproveita os materiais da impotência amorosa em geral (anímica) e sexual em particular (física) da forma como surgem nos Amores. 